\title{
Quavterly Roles of cathepsins in pancreatic cancer
}

\section{(C) Periew}

Department of Gastroenterology \&

Human Nutrition, All India Institute of

Medical Sciences, New Delhi-110029,

India.

Correspondence: Anoop Saraya

Email: ansaraya@yahoo.com

\author{
Nidhi Singh ${ }^{1}$, Anoop Saraya ${ }^{1}$
}

\author{
ABSTRACT
}

Pancreatic cancer is an aggressive disease with rapid invasion and metastasis. Extracellular matrix degrading enzymes play an important role in cancer cell invasion and migration. Cathepsins are a group of proteolytic enzymes, which are responsible for the matrix turnover. Among the cathepsins, more number of studies have focused upon cysteine cathepsins. The function and activities of these enzymes are interwoven and their interplay causes the activation of one another by following a proteolytic cascade. This review focuses on differential expression of cathepsins in different types of pancreatic cancer and controls, importance of cathepsins in various phenomena responsible for tumorigenesis and its spread in experimental and human studies. Thus, cathepsins and its expression in pancreatic cancer may be used as potential biomarkers and may prove to be important therapeutic targets if tested clinically.

KEYWORDS: Cathepsins; invasion; proteases; pancreatic cancer.

\section{Introduction}

Pancreatic cancer is one of the leading causes of cancerrelated deaths with a 5 -year survival rate of only $5 \% .^{1,2}$ At present, surgical resection is possible in $<10 \%$ of patients with pancreatic cancer and post-resection recurrence is seen in $80 \%-90 \%$ of patients. ${ }^{3}$

Central to the process of invasion in cancer is a complex array of matrix-degrading enzymes (proteases), which cause the breakdown of the tissue scaffold. Cathepsins are a subgroup of extracellular matrix degrading proteases, which are reported to be involved in process of invasion of cancer. ${ }^{4-6}$ Cathepsins refers to intracellular proteases that are usually but not exclusively found in lysosomes, and are active at $\mathrm{pH}$ values ranging from neutral to acidic. ${ }^{7}$ At present, there are 11 human cathepsins namely, B, C, F, H, L, K, O, S, V, X and W whose amino acid sequences are known. ${ }^{8,9}$

Cathepsins are ubiquitous proteases that are classified according to their active site. Structural differences between various cathepsins result in variations in their substrate specificity and mechanism of inhibition. They can broadly be classified based on the amino acids present at the active sites, which are essential for their catalytic activity, into serine cathepsins, aspartic cathepsins and cysteine cathepsins.

Serine cathepsins include cathepsin A and G. Cathepsin A is also known as "lysosome protective protein". Cathepsin $\mathrm{G}$ is found in the azurophil granules of neutrophilic polymorphonuclear leukocytes. ${ }^{10}$ It is 
identified to play a vital role in the bone microenvironment by modulating tumor-stromal interactions. ${ }^{11}$

Aspartic cathepsins belong to the pepsin family and include lysosomal protease cathepsin D. It has been postulated that cathepsin $\mathrm{D}$ activates a cascade of proteases involved in the degradation of extracellular matrix by activating cathepsin B and enhancing Matrix metalloproteases-9 (MMP-9) activity. ${ }^{12,13}$

Cysteine cathepsins belong to the family of papain- like proteolytic enzymes principally localized sub-cellularly in the endosomal/lysosomal compartment. Cysteine cathepsins comprise of the following members: $\mathrm{B}, \mathrm{C}, \mathrm{F}, \mathrm{H}, \mathrm{L}, \mathrm{K}, \mathrm{O}, \mathrm{S}, \mathrm{B}, \mathrm{W}, \mathrm{X} / \mathrm{Z}$, all of which share a conserved active site formed by cysteine and histidine residues. ${ }^{14}$ These cysteine proteases can be either endopeptidases or exopeptidases or have both of these activities, resulting in potentially distinct substrate preferences for individual cathepsins.(9) Seven of these proteases, cathepsin B (CTSB), C (dipeptidyl peptidase I), F, H, L (CTSL), $\mathrm{O}$, and $\mathrm{X}$ (alternative names; cathepsin $\mathrm{Z}$; cathepsin $\mathrm{P})$, exhibit ubiquitous but, nevertheless, differential expression in mammalian tissues, whereas other papainlike cysteine proteases (i.e., cathepsins $\mathrm{J}, \mathrm{K}, \mathrm{S}, \mathrm{V}$ and $\mathrm{W}$ ), are only expressed by specific cell types. ${ }^{15,16}$

Physiological functions of cathepsins include bone remodelling, protein turnover, keratinocyte differentiation and apoptosis. ${ }^{5,17-19}$ In normal cells, the acidic $\mathrm{pH}$ of the lysosomes activates them. However upon malignant transformation, instead of being transported into the lysosomal compartment, cathepsins are often translocated to cell-surface and secreted into the surrounding medium. ${ }^{5}$ In addition, some cathepsins viz. cathepsin B and L also work to activate other proteases namely urokinase plasminogen activator system which in turn activates MMPs (Matrix Metalloproteases)(20) (Figure 1). This review has discussed studies that focus on cathepsins in pancreatic cancer.

\section{Role of cathepsins in cancer progression}

Among the various cathepsins, cysteine cathepsins are the most widely studied and among these the lysosomal protease cathepsin B has been studied extensively. Cathepsin $\mathrm{B}$ can be activated by acidic $\mathrm{pH}$ or by various other proteases like cathepsin D, cathepsin G, urokinase plasminogen activator receptor (u-PAR). ${ }^{12,21,22}$ Cathepsin $\mathrm{B}$ can act at as exopeptidases (carboxypeptidases) at low $\mathrm{pH}$ and as endopeptidases at neutral $\mathrm{pH} .^{23,24}$

Various experimental studies have thrown light on the role of cathepsin B on tumorigenesis. (Table 1) Cathepsin B deletion has been shown to decrease in tumor initiation, proliferation, apoptosis, angiogenesis and invasion in transgenic mouse model for pancreatic islet carcinogenesis; this model with ablated cathepsin B was shown to have increased apoptosis..$^{25}$ In an in vivo model of pancreatic ductal adenocarcinoma (PDAC), decrease in cathepsin B expression was not only found to slow down progression of disease in pancreatic Intraepithelial (PanIN) lesions but also in advanced pancreatic cancer due to alteration of mitogen activated protein (MAP) kinase pathway activity. ${ }^{26}$ Dudeja et al. found that downregulation of Heat Shock Protein-70 (HSP-70) in pancreatic cancer cell lines permits release of cathepsin B from lysosomes by permeabilization and this cathepsin $\mathrm{B}$ activates caspase-3 dependent apoptosis. ${ }^{19}$ In a rat insulinoma cell line, cathepsin B was found to increase proinflammatory response and increase in lipotoxicity. ${ }^{27}$ In various type of mouse models namely pancreatic neuroendocrine, pancreatic ductal adenocarcinoma,

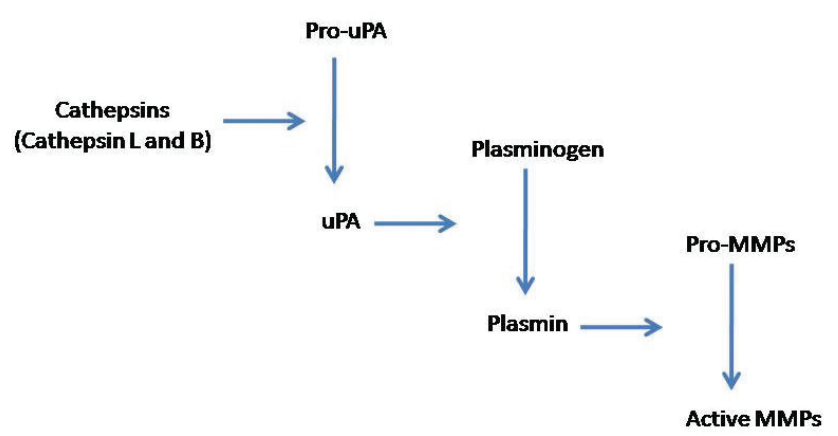

Figure 1: Schematic representation of various steps in the proteolytic cleavage cascade of extracellular matrix degrading enzymes. Cathepsins (cathepsin $B$ and $L$ ) activate urokinase-type plasminogen activator from its inactive form. Therafter, urokinase plasminogen activator converts plasminogen to its active form, plasmin. Plasmin then converts inactive matrix metalloproteinases to their active form. 
Table 1: List of experimental studies highlighting the role of cathepsins in tumor progression.

\begin{tabular}{l|l|l}
\hline $\begin{array}{l}\text { Study (Author, Year) } \\
\text { Brindle et al, 2015 (39) }\end{array}$ & Neuroendocrine pancreatic tumors & $\begin{array}{l}\text { Findings } \\
\text { Cathepsin L contribute to Myc-driven } \\
\text { tumorigenesis }\end{array}$ \\
\hline Reinheckel et al, 2012 (28) & PDAC, Neuroendocrine tumor & $\begin{array}{l}\text { Ablation of cathepsin B leads to decrease in } \\
\text { aggressiveness of the disease }\end{array}$ \\
\hline Gopinathan et al, 2012 (26) & PDAC mouse model & $\begin{array}{l}\text { Decrease in cathepsin B leads to decrease in } \\
\text { disease progression through hampering of MAP } \\
\text { kinase pathway }\end{array}$ \\
\hline Gocheva et al, 2010 (41) & $\begin{array}{l}\text { Pre-malignant hyperplastic lesions in mouse } \\
\text { model }\end{array}$ & $\begin{array}{l}\text { Decrease in cathepsin H expression leads to } \\
\text { decrease in angiogenic switching but increased } \\
\text { apoptosis }\end{array}$ \\
\hline Dudeja et al, 2009 (19) & Pancreatic cancer cell line & $\begin{array}{l}\text { HSP-70 mediated release of cathepsin B from } \\
\text { lysosomes activates caspase-3 dependent } \\
\text { apoptosis }\end{array}$ \\
\hline Gocheva et al, 2006 (25) & $\begin{array}{l}\text { Transgenic pancreatic islet carcinogenesis } \\
\text { mouse model-RIP-Tag2 model }\end{array}$ & $\begin{array}{l}\text { Cathepsin B , L and S ablation decreases tumor } \\
\text { initiation and proliferation, angiogenesis and } \\
\text { invasion. Cathepsin L induces apoptosis }\end{array}$ \\
\hline Wang et al, 2006 (40) & $\begin{array}{l}\text { Murine pancreatic islet cell carcinogenesis } \\
\text { model }\end{array}$ & $\begin{array}{l}\text { Decrease in cathepsin S leads to alteration } \\
\text { in production of pro-angiogenic and anti } \\
\text { angiogenic peptides. }\end{array}$
\end{tabular}

breast cancer and intestinal carcinoma models, deletion of cathepsin B led to suppression of the aggressiveness of the respective cancer phenotype. ${ }^{28}$

Cathepsin L, another member of the group of cysteine proteases, is believed to have endoproteolytic property much stronger than that of cathepsin B., ${ }^{5,29,30}$ Cathepsin L plays its role extracellularly as well as intracellularly. Anaerobic glycolysis in cancer cells creates acidic conditions in the tumor microenvironment which is favorable for cathepsin L activity. ${ }^{31-33}$ Active cathepsin $\mathrm{L}$ degrades collagen, fibronectin and laminin. ${ }^{33}$ By mass spectrophotometry technique, in mouse pancreatic cancer model, cathepsin L and cathepsin S enzymes has been shown to shed from the cancer cells and act on the extracellular domain of cell adhesion molecules at the surface of cancer cells. ${ }^{34}$ Cleavage of a cell-cell adhesion molecule, E-cadherin, by cathepsin L again contributes to the invasive function of cathepsin $\mathrm{L}^{25}$ Apart from matrix degrading function, role of cathepsin L has also been studied in inducing apoptosis by cleaving BID (BH3 interacting-domain death agonist), a pro-apoptotic molecule involved in apoptotic pathway. ${ }^{35,36}$ The role of cathepsin L in promoting tumor cell proliferation, tumor growth and angiogenesis has been elucidated in RIP-Tag2 transgenic mouse model for pancreatic islet cell carcinogenesis. ${ }^{25,37}$ Cathepsin $\mathrm{L}$ is also involved in processing of transcription factor, $\mathrm{CDP} / \mathrm{Cux}$, responsible for rapid transition of cancer cells into $\mathrm{S}$ phase of the cell cycle. ${ }^{38}$ Cathepsin L has been recently found to contribute to the Myc-driven tumorigenesis in neuroendocrine pancreatic tumors. ${ }^{39}$

Both cathepsin $\mathrm{S}$ and cathepsin $\mathrm{H}$ were found to have role in tumor angiogenesis. Downregulation of cathepsin $\mathrm{S}$ was shown to alter the production of antiangiogenic peptides and the production of pro-angiogenic protein called- $\gamma 2$ fragmin, impairing the process of angiogenesis. ${ }^{40}$ Cathepsin $\mathrm{H}$ knockout in an in vivo study, resulted in decreased angiogenic switching in pre-malignant hyperplastic islets and reduced development of tumor in RIP-Tag2 mouse model. ${ }^{41}$ Furthermore, homozygous cathepsin $\mathrm{H}$ deletion was found to increase apoptosis. ${ }^{41}$ 
Cathepsin D, a member of aspartic protease family, apart from its immune function, also behaves as a mitogen and participates in tumor growth. ${ }^{42}$ Cathepsin $\mathrm{D}$ is present in three forms, pro-cathepsin D form (enzymatically inactive), intermediate single chain form (enzymatically active), and mature form (enzymatically active). ${ }^{43}$ Enzymatically active forms are responsible for autophagy and apoptotic pathway modulation, which are required for cell control and homeostasis while pro cathepsin D help degrade extracellular matrix and help in invasion. Thus, different forms of this protease are responsible for different role in malignant and benign neoplasm.

Cathepsin Z secreted from pancreatic cancer cells aids in cell proliferation while cathepsin $\mathrm{Z}$ contributed by cancer cells and macrophages together contribute to tumor invasion, thus, emphasizing the role of cathepsins and tumor microenvironment in tumor spread. ${ }^{44}$

\section{Interactions between cathepsins and other proteases seen in pancreatic cancer}

In a recent study on murine model of pancreatic neuroendocrine tumor, in a knockout mouse deficient in cathepsin B and cathepsin S, tumor promoting function was restored by newly identified cathepsin $\mathrm{Z}$ indicating that multiple cathepsins work towards tumor progression. In addition, some cathepsins viz. cathepsin B and L also work to activate other proteases namely urokinase plasminogen activator system which in turn activates matrix metalloproteases (Figure 1). ${ }^{20,45}$

\section{Regulation of cathepsins}

Cathepsins and their function are regulated in pancreatic cancer. Metastasis-associated anterior gradient-2 molecule, present at the surface of tumor cells, was found to regulate the expression of cathepsin B and cathepsin $\mathrm{D}$ and contribute to the metastasis of pancreatic cancer cells in vivo. ${ }^{46}$ Overexpression of Hedgehog protein was found to activate its downstream molecule cathepsin B that is responsible for inducing invasion in pancreatic cancer cells. ${ }^{47}$ Another study found that upregulation and downregulation of S100 BP has an effect on the expression of cathepsin Z, and silencing of cathesin Z leads to decreased cell adhesion in pancreatic cancer cells. $^{48}$

\section{Clinical significance of cathepsins in pancreatic cancer}

Cathepsin B is expressed more in pancreatic intraepithelial lesions than in normal pancreas in in vivo studies. ${ }^{26}$ Cathepsin B was expressed in $96 \%$ of pancreatic tumor tissue of surgically resected patients and it also predicted the recurrence of the disease after surgical resection. ${ }^{49}$ Higher cathepsin B expression in pancreatic tumor tissue was found to correlate with perineural invasion and survival after surgery. ${ }^{50}$ Cathepsin B was able to differentiate invasive tubular adenocarcinoma having expression in $70 \%$ of tumor tissue cases from intraductal papillary adenocarcinomas with no cathepsin B expression. ${ }^{51}$ Increased gene expression of cathepsin B was noted not only in tumor cells but also in macrophages and fibroblasts in peritumoral stroma. ${ }^{49}$

Cathepsin L has been found to be overexpressed in pancreatic cancer tumor tissue. ${ }^{49,52}$ In a mouse model, cathepsin L expression was more in PanIn lesions and early stage pancreatic ductal adenocarcinoma with little expression in normal and inflammed pancreas ${ }^{53}$ indicating a possible role of cathepsin L in identifying early stages of pancreatic cancer. Higher cathepsin L expression has been reported to correlate significantly with post-operative survival. ${ }^{49}$ However, in their later study, these authors assessed cathepsin L and cathepsin B expression in tumors tissues from 70 cases of carcinomas of pancreas and they found that both cathepsin B and cathepsin L expression correlated with overall survival but only cathepsin B expression was found to be a significant independent prognostic marker. ${ }^{50}$ Furthermore, epithelial expression of cathepsin L in pancreatic tumor tissue was found to associate with survival. ${ }^{54}$ Serum and plasma cathepsin L levels were found to be elevated in patients with PDAC as compared to healthy individuals and chronic pancreatitis patients. ${ }^{55,56}$ Singh et al also reported plasma cathepsin $\mathrm{L}$ to be an independent prognostic marker for pancreatic cancer. $^{56}$

Among other cathepsins, cathepsin $\mathrm{H}$ and cathepsin $\mathrm{S}$ were found to be upregulated in pancreatic cancer cell 
line. ${ }^{57,58}$ These were also upregulated in a mouse model of endocrine tumors. ${ }^{37}$ Cathepsin $\mathrm{H}$ was also expressed in insulinoma cells. ${ }^{59}$ Cathepsin $\mathrm{S}$ was demonstrated to have high degree of immunoreactivity in PanIN lesions and early stage pancreatic ductal adenocarcinoma in mouse models. ${ }^{53}$

Cathepsin D is overexpressed in pancreatic cancer as well as in chronic pancreatitis cases. ${ }^{60,61}$ Combination of Cathepsin D with CA19-9 and MMP-7 was reported to be an important panel of markers for screening PDAC. ${ }^{17}$ Cathepsin D immunoreactivity was observed in ductal as well as in stromal cells of pancreatic tumor tissue with significantly higher expression in ductal cells while in normal pancreas immunoreactivity was found only in ductal cells and not in stromal cells. ${ }^{60}$ Interestingly, cathepsin D levels in serum of chronic pancreatitis patients was found to be more than that in normal individuals or pancreatic cancer patients. ${ }^{55}$ Such results should be looked at carefully as different forms of cathepsin D perform different functions as discussed earlier in this review. ${ }^{62}$

Cathepsin E is another aspartic proteinase, which is non-secretory. It is expressed intracellularly and in high quantity in pancreatic cancer, as well as in mucinous cell hyperplasia and intraductal papillary hyperplasia. ${ }^{29,63,64}$ The fact that cathepsin $\mathrm{E}$ is overexpressed in intraductal papillary mucinous tumor of the pancreas as well as pancreatic adenocarcinomas suggests that cathepsin E acts at an early stage of the disease. ${ }^{65}$ Over expression of cathepsin E gene can be utilized to differentiate between malignant and non-malignant conditions. ${ }^{65}$ However, there are some reports that show the detection of cathepsin $\mathrm{E}$ in chronic pancreatitis patients also but not in normal pancreas. ${ }^{63,65,66}$

\section{Cathepsins as therapeutic targets in pancreatic cancer therapy}

Various small molecule cathepsin inhibitors that have been tested preclinically in animal models include vinyl sulfones, nitriles and epoxy-succinil-based compounds. ${ }^{67,68}$ A reversible cathepsin inhibitor, VBY825, has been shown to inhibit cathepsin B, L, S and V in a pre-clinical study on pancreatic islet cell tumor and has been found to reduce the tumor burden and number. ${ }^{67}$
Cystatins, which are endogenous molecules, are known to inhibit lysosomal cysteine proteinases; Cystatin E/M which were overexpressed in PDAC were found to inhibit intracellular proteases. ${ }^{69} \mathrm{~A}$ small molecular selective inhibitor, Z-Phe-Arg-fluoromethylketone (Z-Phe-ArgFMK), showed significant reduction in tumor growth in moderately differentiated tumors but no effect on poorly differentiated tumors. ${ }^{70}$ JPM-OEt, an irreversible cathepsin inhibitor, has been found to decrease tumor growth, vascularity and invasiveness in RIP-Tag2 transgenic mouse model. ${ }^{37}$ However, clinical trials are needed to imply these inhibitors in therapy, either alone or in combination with existing chemotherapeutic and radiotherapeutic regimens.

Some recent studies have used cathepsins as drug delivery systems. Cathepsin B has been useful for rapid drug release inside lysosomes. ${ }^{71}$ With the aim of the targeted action of the drug, a prodrug 5-aminolevulinic acid (ALA) was designed in such a way that its gets activated with the help of cathepsin E present in cancer cells of pancreatic ductal adenocarcinoma leading to targeted action of the drug. ${ }^{72}$ Another example of the role of cathepsins in prodrug activation is of cathepsin D activating 5'-O-L-phenylalanyl-L-tyrosylfloxuridine in pancreatic cancer cell lines. ${ }^{73}$ Radiotherapeutic drug designed with metabolically activable linkers (MAL) having enzymatically cleavable sites for cathepsin B and $\mathrm{S}$, has been shown to decrease non-target drug retention and drug toxicity in a pancreatic cancer model. ${ }^{74}$ Similarly, Cathepsin S susceptible linkers (CSL) improve the nontarget clearance of N-(2-hydroxypropyl)-methacrylamide (HPMA) copolymers and more accurate imaging. ${ }^{75}$ Despite great number of preclinical studies, there are so far no clinical studies in humans that study the usefulness of cathepsins in pancreatic cancer therapy.

\section{Cathepsins as screening probe for pancreatic cancer}

Cathepsin E activable probe has been studied as an in vivo screening test for PanIn lesions and PDAC through confocal microscopy. ${ }^{76}$ The cathepsin $\mathrm{E}$ sensitive fluorescent probe was not only able to detect specifically PDAC in human xenografts and genetically modified mouse model but was also able to detect pancreas with 
PanIN lesions in genetically engineered mouse model before tumor formation in an optical imaging systems. ${ }^{65}$ In a genetically defined mouse model of PDAC, PanIN lesions were found to be detectable with the help of cathepsin (cathepsin B, H, L and S) activation by near infrared probe in a confocal fluorescence laser microscope. ${ }^{53}$ HPMA copolymers have been shown to diagnose and stage the pancreatic cancers but they accumulate in non-target locations like liver, which can be cleared with the help of cathepsin S cleavable linkers. ${ }^{75}$ A novel FDA (Food and Drug Administration) approved protease inhibitor with high affinity to cathepsin $\mathrm{E}$ has been shown to demarcate cancer cells and can be of great help in deciding margins for surgical resection. ${ }^{77}$ These are all preclinical studies and clinical studies are needed to use cathepsins as screening probe.

In conclusion, a large amount of data suggests the role of cathepsins in different aspects of cancer, including some preclinical experience as screening and therapeutic targets. Thus, efficacy of cathepsins as markers and therapeutic targets should be assessed clinically.

\section{References}

1. DiMagno EP. Pancreatic cancer: clinical presentation, pitfalls and early clues. Ann Oncol 1999;10 Suppl. 4:140142.

2. Wray CJ, Ahmad SA, Matthews JB, et al. Surgery for pancreatic cancer: recent controversies and current practice. Gastroenterology. 2005;128:1626-1641.

3. Yeo CJ. Management of complications following pancreaticoduodenectomy. Surg Clin North Am. 1995;75:913-924.

4. Coulibaly S, Schwihla H, Abrahamson M, et al. Modulation of invasive properties of murine squamous carcinoma cells by heterologous expression of cathepsin B and cystatin C. Int J Cancer. 1999;83:526-531.

5. Mohamed MM, Sloane BF. Cysteine cathepsins: multifunctional enzymes in cancer. Nat Rev Cancer. 2006;6:764-775.

6. Roshy S, Sloane BF, Moin K. Pericellular cathepsin $\mathrm{B}$ and malignant progression. Cancer Metastasis Rev. 2003;22:271-286.

7. Mason RW, Gal S, Gottesman MM. The identification of the major excreted protein (MEP) from a transformed mouse fibroblast cell line as a catalytically active precursor form of cathepsin L. Biochem J. 1987;248:449-454.

8. Turk B, Turk D, Turk V. Lysosomal cysteine proteases: more than scavengers. Biochim Biophys Acta. 2000;1477:98111.

9. Turk V, Turk B, Turk D. Lysosomal cysteine proteases: facts and opportunities. EMBO J. 2001;20:4629-4633.

10. Thomas EL, Lehrer RI, Rest RF. Human neutrophil antimicrobial activity. Rev Infect Dis. 1988;10 Suppl. 2:S450-456.

11. Wilson TJ, Nannuru KC, Singh RK. Cathepsin G recruits osteoclast precursors via proteolytic activation of proteaseactivated receptor-1. Cancer Res. 2009;69:3188-3195.

12. van der Stappen JW, Williams AC, Maciewicz RA, et al. Activation of cathepsin B, secreted by a colorectal cancer cell line requires low $\mathrm{pH}$ and is mediated by cathepsin $\mathrm{D}$. Int J Cancer. 1996;67:547-554.

13. Hu L, Roth JM, Brooks $\mathrm{P}$, et al. Thrombin up-regulates cathepsin D which enhances angiogenesis, growth, and metastasis. Cancer Res. 2008;68:4666-4673.

14. Turk D, Guncar G. Lysosomal cysteine proteases (cathepsins): promising drug targets. Acta Crystallogr D Biol Crystallogr. 2003;59:203-213.

15. Rawlings ND, Barrett AJ. Evolution of proteins of the cystatin superfamily. J Mol Evol. 1990;30:60-71.

16. Deussing J, Kouadio M, Rehman S, et al. Identification and characterization of a dense cluster of placenta-specific cysteine peptidase genes and related genes on mouse chromosome 13. Genomics. 2002;79:225-240.

17. Giusti I, D'Ascenzo S, Millimaggi D, et al. Cathepsin B mediates the $\mathrm{pH}$-dependent proinvasive activity of tumorshed microvesicles. Neoplasia. 2008;10:481-488.

18. Turk V, Kos J, Turk B. Cysteine cathepsins (proteases)-on the main stage of cancer? Cancer Cell. 2004;5:409-410.

19. Dudeja V, Mujumdar N, Phillips P, et al. Heat shock protein 70 inhibits apoptosis in cancer cells through simultaneous and independent mechanisms. Gastroenterology. 2009;136:1772-1782.

20. Gocheva V, Joyce JA. Cysteine cathepsins and the cutting edge of cancer invasion. Cell Cycle. 2007;6:60-64.

21. Dalet-Fumeron V, Guinec N, Pagano M. In vitro activation of pro-cathepsin B by three serine proteinases: leucocyte elastase, cathepsin G, and the urokinase-type plasminogen activator. FEBS Lett. 1993;332:251-254.

22. Dalet-Fumeron V, Boudjennah L, Pagano M. Competition between plasminogen and procathepsin $\mathrm{B}$ as a probe to demonstrate the in vitro activation of procathepsin B by 
the tissue plasminogen activator. Arch Biochem Biophys. 1996;335:351-357.

23. Musil D, Zucic D, Turk D, et al. The refined 2.15 A X-ray crystal structure of human liver cathepsin B: the structural basis for its specificity. EMBO J. 1991;10:2321-2330.

24. Keppler D, Sloane BF. Cathepsin B: multiple enzyme forms from a single gene and their relation to cancer. Enzyme Protein. 1996;49:94-105.

25. Gocheva V, Zeng W, Ke D, et al. Distinct roles for cysteine cathepsin genes in multistage tumorigenesis. Genes Dev. 2006;20:543-556.

26. Gopinathan A, Denicola GM, Frese KK, et al. Cathepsin B promotes the progression of pancreatic ductal adenocarcinoma in mice. Gut. 2012;61:877-884.

27. Li S, Du L, Zhang L, et al. Cathepsin B contributes to autophagy-related 7 (Atg7)-induced nod-like receptor 3 (NLRP3)-dependent proinflammatory response and aggravates lipotoxicity in rat insulinoma cell line. $J$ Biol Chem. 2013;288:30094-30104.

28. Reinheckel T, Peters C, Kruger A, et al. Differential Impact of Cysteine Cathepsins on Genetic Mouse Models of De novo Carcinogenesis: Cathepsin B as Emerging Therapeutic Target. Front Pharmacol. 2012;3:133.

29. Chwieralski CE, Welte T, Buhling F. Cathepsin-regulated apoptosis. Apoptosis. 2006;11:143-149.

30. Wartmann T, Mayerle J, Kahne T, et al. Cathepsin L inactivates human trypsinogen, whereas cathepsin L-deletion reduces the severity of pancreatitis in mice. Gastroenterology. 2010;138:726-737.

31. Hashimoto Y, Kondo C, Kojima T, et al. Significance of 32-kDa cathepsin L secreted from cancer cells. Cancer Biother Radiopharm. 2006;21:217-224.

32. Rofstad EK, Mathiesen B, Kindem K, et al. Acidic extracellular $\mathrm{pH}$ promotes experimental metastasis of human melanoma cells in athymic nude mice. Cancer Res. 2006;66:6699-6707.

33. Skrzydlewska E, Sulkowska M, Koda M, et al. Proteolyticantiproteolytic balance and its regulation in carcinogenesis. World J Gastroenterol. 2005;11:1251-1266.

34. Sobotic B, Vizovisek M, Vidmar R, et al. Proteomic Identification of Cysteine Cathepsin Substrates Shed from the Surface of Cancer Cells. Mol Cell Proteomics. 2015; 14:2213-2228.

35. Stoka V, Turk B, Schendel SL, et al. Lysosomal protease pathways to apoptosis. Cleavage of bid, not pro-caspases, is the most likely route. J Biol Chem. 2001;276:3149-3157.

36. Green DR, Reed JC. Mitochondria and apoptosis. Science.
1998;281:1309-1312.

37. Joyce JA, Baruch A, Chehade K, et al. Cathepsin cysteine proteases are effectors of invasive growth and angiogenesis during multistage tumorigenesis. Cancer Cell. 2004;5:443453.

38. Goulet B, Sansregret L, Leduy L, et al. Increased expression and activity of nuclear cathepsin L in cancer cells suggests a novel mechanism of cell transformation. Mol Cancer Res. 2007;5:899-907.

39. Brindle NR, Joyce JA, Rostker F, et al. Deficiency for the cysteine protease cathepsin L impairs Mycinduced tumorigenesis in a mouse model of pancreatic neuroendocrine cancer. PLoS One. 2015;10:e120348.

40. Wang B, Sun J, Kitamoto S, et al. Cathepsin S controls angiogenesis and tumor growth via matrix-derived angiogenic factors. $J$ Biol Chem. 2006;281:6020-6029.

41. Gocheva V, Chen X, Peters C, et al. Deletion of cathepsin H perturbs angiogenic switching, vascularization and growth of tumors in a mouse model of pancreatic islet cell cancer. Biol Chem. 2010;391:937-945.

42. Nomura T, Katunuma N. Involvement of cathepsins in the invasion, metastasis and proliferation of cancer cells. $J$ Med Invest. 2005;52:1-9.

43. Nicotra G, Castino R, Follo C, et al. The dilemma: does tissue expression of cathepsin D reflect tumor malignancy? The question: does the assay truly mirror cathepsin D misfunction in the tumor? Cancer Biomark. 2010;7:47-64.

44. Akkari L, Gocheva V, Kester JC, et al. Distinct functions of macrophage-derived and cancer cell-derived cathepsin $\mathrm{Z}$ combine to promote tumor malignancy via interactions with the extracellular matrix. Genes Dev;28:2134-2150.

45. Akkari L, Gocheva V, Quick ML, et al. Combined deletion of cathepsin protease family members reveals compensatory mechanisms in cancer. Genes Dev. 2016;30:220-232.

46. Dumartin L, Whiteman HJ, Weeks ME, et al. AGR2 is a novel surface antigen that promotes the dissemination of pancreatic cancer cells through regulation of cathepsins B and D. Cancer Res. 2011;71:7091-7102.

47. Hwang JH, Lee SH, Lee $\mathrm{KH}$, et al. Cathepsin B is a target of Hedgehog signaling in pancreatic cancer. Cancer Lett. 2009;273:266-272.

48. Lines KE, Chelala C, Dmitrovic B, et al. S100P-binding protein, $\mathrm{S} 100 \mathrm{PBP}$, mediates adhesion through regulation of cathepsin Z in pancreatic cancer cells. Am J Pathol. 2012;180:1485-1494.

49. Niedergethmann $M$, Hildenbrand $R$, Wolf $G$, et al. Angiogenesis and cathepsin expression are prognostic 
factors in pancreatic adenocarcinoma after curative resection. Int J Pancreatol. 2000;28:31-39.

50. Niedergethmann M, Wostbrock B, Sturm JW, et al. Prognostic impact of cysteine proteases cathepsin B and cathepsin L in pancreatic adenocarcinoma. Pancreas. 2004;29:204-211.

51. Ohta T, Terada T, Nagakawa T, et al. Pancreatic trypsinogen and cathepsin B in human pancreatic carcinomas and associated metastatic lesions. Br J Cancer. 1994;69:152156.

52. Singh N, Das P, Datta Gupta S, et al. Prognostic significance of extracellular matrix degrading enzymes-cathepsin $\mathrm{L}$ and matrix metalloproteases-2 [MMP-2] in human pancreatic cancer. Cancer Invest;31:461-471.

53. Eser $\mathrm{S}$, Messer M, Eser $\mathrm{P}$, et al. In vivo diagnosis of murine pancreatic intraepithelial neoplasia and early-stage pancreatic cancer by molecular imaging. Proc Natl Acad Sci U S A. 2011;108:9945-9950.

54. Singh N, Das P, Datta Gupta S, et al. Prognostic significance of extracellular matrix degrading enzymes-cathepsin $\mathrm{L}$ and matrix metalloproteases-2 [MMP-2] in human pancreatic cancer. Cancer Invest. 2013;31:461-471.

55. Leto G, Tumminello FM, Pizzolanti G, et al. Lysosomal aspartic and cysteine proteinases serum levels in patients with pancreatic cancer or pancreatitis. Pancreas. 1997; 14:22-27.

56. Singh N, Das P, Gupta S, et al. Plasma cathepsin L: a prognostic marker for pancreatic cancer. World $J$ Gastroenterol. 2014;20:17532-17540.

57. Paciucci R, Berrozpe G, Tora M, et al. Isolation of tissuetype plasminogen activator, cathepsin $\mathrm{H}$, and non-specific cross-reacting antigen from SK-PC-1 pancreas cancer cells using subtractive hybridization. FEBS Lett. 1996;385:7276.

58. Kwok HF, Buick RJ, Kuehn D, et al. Antibody targeting of Cathepsin S induces antibody-dependent cellular cytotoxicity. Mol Cancer. 2011;10:147.

59. Im B, Kominami E, Grube D, et al. Immunocytochemical localization of cathepsins $\mathrm{B}$ and $\mathrm{H}$ in human pancreatic endocrine cells and insulinoma cells. Histochemistry. 1989;93:111-118.

60. Chen R, Brentnall TA, Pan S, et al. Quantitative proteomics analysis reveals that proteins differentially expressed in chronic pancreatitis are also frequently involved in pancreatic cancer. Mol Cell Proteomics. 2007;6:13311342.

61. Shen J, Person MD, Zhu J, et al. Protein expression profiles in pancreatic adenocarcinoma compared with normal pancreatic tissue and tissue affected by pancreatitis as detected by two-dimensional gel electrophoresis and mass spectrometry. Cancer Res. 2004;64:9018-9026.

62. Ulbricht B, Henny H, Horstmann H, et al. Influence of 12(S)-hydroxyeicosatetraenoic acid (12(S)-HETE) on the localization of cathepsin B and cathepsin L in human lung tumor cells. Eur J Cell Biol. 1997;74:294-301.

63. Terris B, Blaveri E, Crnogorac-Jurcevic T, et al. Characterization of gene expression profiles in intraductal papillary-mucinous tumors of the pancreas. Am J Pathol. 2002;160:1745-1754.

64. Azuma T, Hirai M, Ito $\mathrm{S}$, et al. Expression of cathepsin $\mathrm{E}$ in pancreas: a possible tumor marker for pancreas, a preliminary report. Int J Cancer. 1996;67:492-497.

65. Cruz-Monserrate Z, Abd-Elgaliel WR, Grote T, et al. Detection of pancreatic cancer tumours and precursor lesions by cathepsin E activity in mouse models. Gut. 2012;61:1315-1322.

66. Fukushima N, Sato N, Prasad N, et al. Characterization of gene expression in mucinous cystic neoplasms of the pancreas using oligonucleotide microarrays. Oncogene. 2004;23:9042-9051.

67. Elie BT, Gocheva V, Shree T, et al. Identification and preclinical testing of a reversible cathepsin protease inhibitor reveals anti-tumor efficacy in a pancreatic cancer model. Biochimie. 2010;92:1618-1624.

68. Palermo C, Joyce JA. Cysteine cathepsin proteases as pharmacological targets in cancer. Trends Pharmacol Sci. 2008;29:22-28.

69. Hosokawa M, Kashiwaya K, Eguchi H, et al. Overexpression of cysteine proteinase inhibitor cystatin 6 promotes pancreatic cancer growth. Cancer Sci. 2008;99:1626-1632.

70. Van Noorden CJ, Jonges TG, Meade-Tollin LC, et al. In vivo inhibition of cysteine proteinases delays the onset of growth of human pancreatic cancer explants. Br J Cancer. 2000;82:931-936.

71. Fang Y, Du F, Xu Y, et al. Enhanced cellular uptake and intracellular drug controlled release of VESylated gemcitabine prodrug nanocapsules. Colloids Surf B Biointerfaces. 2015;128:357-362.

72. Abd-Elgaliel WR, Cruz-Monserrate Z, Wang H, et al. Pancreatic cancer-associated Cathepsin E as a drug activator. J Control Release. 2013;167:221-227.

73. Tsume Y, Amidon GL. The feasibility of enzyme targeted activation for amino acid/dipeptide monoester prodrugs of 
floxuridine; cathepsin D as a potential targeted enzyme. Molecules. 2012;17:3672-3689.

74. Ogbomo SM, Shi W, Wagh NK, et al. 177Lu-labeled HPMA copolymers utilizing cathepsin B and S cleavable linkers: synthesis, characterization and preliminary in vivo investigation in a pancreatic cancer model. Nucl Med Biol. 2013;40:606-617.

75. Shi W, Ogbomo SM, Wagh NK, et al. The influence of linker length on the properties of cathepsin $\mathrm{S}$ cleavable
(177)Lu-labeled HPMA copolymers for pancreatic cancer imaging. Biomaterials. 2014;35:5760-5770.

76. Li H, Li Y, Cui L, et al. Monitoring pancreatic carcinogenesis by the molecular imaging of cathepsin $\mathrm{E}$ in vivo using confocal laser endomicroscopy. PLoS One. 2014;9:e106566.

77. Keliher EJ, Reiner T, Earley S, et al. Targeting cathepsin $\mathrm{E}$ in pancreatic cancer by a small molecule allows in vivo detection. Neoplasia. 2013;15:684-693. 